\title{
Векторы сбережения человеческого капитала в системе современных правовых преобразований
}

\author{
${ }^{1}$ Бутько Л.В., ${ }^{2}$ Лепешкина О.В. \\ ${ }^{1}$ Северо-Кавказский филиал Российского государственного университета правосудия \\ Россия, 308015, г. Краснодар, ул. Леваневского, 187/1 \\ E-mail: lvbutko@mail.ru \\ ${ }^{2}$ Кубанский государственный университет, \\ Россия, 350040, г. Краснодар, ул. Ставропольская, 149 \\ E-mail: ovlepeshkina@mail.ru
}

\begin{abstract}
Аннотация. Рассмотрены проблемы правового регулирования одного из ключевых векторов сбережения человеческого капитала - сферы мировоззрения, идеологии, нравственности через призму соотношения сознания, правосознания и права. Автором проведен анализ правовых, исторических, философских и иных источников в контексте конституционных изменений 2020 года с целью обоснования приоритетности исследуемой сферы как идеологического вектора сбережения человеческого капитала с использованием комплекса общенаучных, междисциплинарных и частно-научных методов. В процессе анализа рассмотрена последовательность суждений об актуализации вопросов сбережения человеческого капитала в современном мире, дано обоснование приоритетности сферы правового регулирования для успешного сбережения человеческого капитала, определена роль сознания и правосознания в формировании идеологических основ жизни человеческого сообщества. В результате исследования сделаны выводы о противоречиях правосознания и права, предложены варианты их разрешения; представлены роль и значение многоаспектности правосознания в механизмах сбережения человеческого капитала; с философских позиций обоснована целесообразность дефинитивного и методологического обновления концептуальных положений учения о правовом регулировании общественных отношений в сфере сбережения человеческого капитала.
\end{abstract}

Ключевые слова: сбережение человеческого капитала, приоритетность, мировоззрение, нравственность, идеологический вектор, конституция, правовое регулирование, правосознание.

Для цитирования: Бутько Л.В., Лепешкина О.В. 2021. Векторы сбережения человеческого капитала в системе современных правовых преобразований. NOMOTHETIKA: Философия. Социология. Право. 46 (3): 524-532. DOI: 10.52575/2712-746X-2021-46-3-524-532

\section{Vectors of Saving Human Capital in the System of Modern Legal Transformations}

\author{
${ }^{1}$ Ludmila V. Butko, ${ }^{2}$ Olga V. Lepeshkina \\ ${ }^{1}$ North-Caucasian branch of the of the Russian State University of Justice, \\ Levanevsky str., 187/1, Krasnodar, 350002, Russia \\ E-mail: lvbutko@mail.ru \\ ${ }^{2}$ Kuban State University, \\ 149 Stavropol St, Krasnodar, 350040, Russia \\ E-mail: ovlepeshkina@mail.ru
}

Abstract. The article is devoted to the problems of legal regulation of one of the key vectors of saving human capital-the sphere of worldview, ideology, morality through the prism of the correlation of 
consciousness, legal consciousness and law. The author analyzes legal, historical, philosophical and other sources in the context of the constitutional changes of 2020 in order to substantiate the priority of the studied sphere as an ideological vector of saving human capital using a complex of general scientific, interdisciplinary and private scientific methods. In the course of the analysis, the sequence of judgments on the actualization of the issues of saving human capital in the modern world is considered, the justification of the priority of the sphere of legal regulation for the successful saving of human capital is given, the role of consciousness and legal consciousness in the formation of the ideological foundations of the life of the human community is determined. As a result of the research, conclusions are drawn about the contradictions of legal consciousness and law, options for their resolution are proposed; the role and significance of the multidimensional legal consciousness in the mechanisms of saving human capital are presented; the expediency of a definitive and methodological update of the conceptual provisions of the doctrine on the legal regulation of public relations in the field of saving human capital is justified from a philosophical point of view.

Keywords: saving of human capital, priority, worldview, morality, ideological vector, con-stitution, legal regulation, legal awareness.

For citation: Butko L.V., Lepeshkina O.V. 2021. Vectors of Saving Human Capital in the System of Modern Legal Transformations. NOMOTHETIKA: Philosophy. Sociology. Law series. 46 (3): 524-532 (in Russian). DOI: 10.52575/2712-746X-2021-46-3-524-532

\section{Введение}

Современная ситуация в мире и в стране, обусловленная целым рядом долговременных факторов и краткосрочных обстоятельств, с нарастанием актуализировала проблемы сбережения главного достояния жизни на планете - человеческого капитала. Совершенно очевидно, что его состояние и возможности сбережения поставлены в прямую зависимость от направлений и динамики процессов политического, социальноэкономического, духовного, правового и иного развития институтов общества и государства, влияния на них явлений экологического, климатического, техногенного и иного характера. Прямое или косвенное воздействие на происходящее оказывают общемировые явления, такие как глобализация, экономическая и иная интеграции, регионализация и другие. Большое значение имеют события, связанные с объявленной во всем мире пандемией COVID-19 и вводимыми по этим причинам ограничительными мерами.

В итоге повышенная степень актуализации проблем сбережения человеческого капитала придает ему роль ведущего, ключевого фактора национальной безопасности государств, сохранения их территориальной целостности, культурно-исторического наследия и национального традиционализма. Убедительность констатируемой актуализации продемонстрировали проявленные в ходе обсуждения и принятия изменений Конституции Российской Федерации в 2020 году их многогранность и неисключаемая противоречивость. Совокупность указанных обстоятельств, формируя специфику текущего момента, предопределила необходимость обновления и трансформации всей системы правового регулирования в стране и в первую очередь в сфере сбережения человеческого капитала, совершенствования его способов.

Указанная задача подвела ученых-юристов и практиков к выбору основных направлений предлагаемых изменений, сфокусировала их внимание на главных проблемах правового регулирования и поиске их решения. В числе причин назовем противоречивость, несогласованность и коррупциогенный характер действующих на данный момент норм права, как отечественного, так и международного. В равной степени имеет место сложность в выборе приоритетности сфер правового регулирования. События последних лет, происходящие и наблюдаемые в мировом масштабе, обнажили глубинные противоре- 
чия и убедили в невозможности достижения единообразных позиций договаривающихся сторон при принятии взаимоприемлемых решений.

\section{Выбор приоритетной сферы правового регулирования для успешного сбережения человеческого капитала}

Вопрос о выборе норм права, которые надлежит реформировать в первую очередь, приобрел судьбоносный характер. Напомним, что определяющими для сохранения человеческого капитала традиционно признаются:

a) нормы экономического права, регулирующие сферу кризисной во всем мире экономики с намерениями создания новой модели отношений хозяйствования и собственности. К примеру, не способствуют сбережению человеческого капитала различные программы глобализации, коренным образом изменившие механизмы перемещения финансов и капитала на территории планеты, придавшие объектам собственности и рабочей силе всеобъемлющий международный характер;

б) нормы социального права, призванного стабилизировать социальную сферу с постановкой целей обеспечения достаточного и достойного уровня жизни населения страны. К примеру, не могут оставаться незамеченными кризисные явления, наблюдаемые в управлении миграционными процессами; совершенно недопустимые, а порой и угрожающие масштабы приобрела торговля людьми (причем первенство занимает торговля женщинами и детьми и только $2 \%$ такого товара приходится на долю мужчин); усиливают тревогу состояние здоровья населения, рост смертности, обнищанье масс и другие явления;

в) нормы, регулирующие сферу власти и политики в условиях противоборства идеологий и оппозиционирования, оказывающие активное влияние на правосознание всех и каждого, в особенности в период проходящей в стране кампании по выборам депутатов Государственной Думы.

Не менее привлекательным выглядит программирование и правовое регулирование вопросов цифровизации информационного пространства, вышедших на первое место в последние годы. В перечисляемой совокупности особое внимание следует уделить совершенствованию норм, регламентирующих сферу нравственного наполнения всех аспектов деятельности человека. Именно этому направлению мы отдаем предпочтение и попытаемся подтвердить его приоритет в укреплении и прирастании человеческого капитала с надеждой, что решение всех иных предполагаемых проблем последует за решением приоритетной.

Учитывая тот факт, что состояние правового регулирования всех сфер общественных отношений порождает серьезные сомнения в возможности построения перспективной программы совершенствования, рассмотрим предлагаемое направление в ключе принятых конституционных поправок. Решение этой многотрудной задачи, на наш взгляд, невозможно без учета российского традиционализма, отечественного позитивного опыта и ранее допущенных ошибок.

\section{Сфера нравственности}

\section{как идеологический вектор сбережения человеческого капитала}

В зоне особого внимания в конституционных поправках оказалась сфера мировоззрения, идеологии, нравственности, которая получила четкую констатацию в качестве предмета правового регулирования на конституционном уроне. Ее значение в системе факторов сбережения человеческого капитала невозможно переоценить, и все потому, что в современном глобализующемся мире авторитет традиционных нравственных ценностей стремительно снижается, несмотря на то, что именно эта сфере функционирования каждого человека наполняет его жизнь духовным содержанием и определяет смысл всей его жизни, формирует его стержень. 
Одна из новелл Конституции посвящена упоминанию в ней веры в Бога (п. 2 ст. 67 Конституции РФ). С предложением о ее отражении в изменениях Конституции к разработчикам поправок обратился Патриарх РПЦ Кирилл, огласив его 1 февраля 2020 г. на мероприятии, посвященном 11-летию его патриаршего служения: «Общими усилиями и молитвами мы будем содействовать тому, чтобы такая возвышенная идея, каковой является вера в Бога, которая формирует нравственность и личную, и общественную, и политическую, чтобы она присутствовала, в том числе и в нашей Конституции». Такая же нравственно-идеологическая направленность отражена и в п.п. 3, 4 указанной выше статьи Основного закона России.

Данное направление совершенствования конституционных предписаний предназначено для реализации в праве признаков двух течений - либерального и традиционалистского, превалирующих в отечественном мировоззренческом информационном пространстве. Опираясь на них, оно вносит в правовое регулирование идеологический контекст и должно рассматриваться как важный вектор сбережения человеческого капитала. Тем самым учреждена конституционная база дальнейшего юридического оформления традиционалистской идеологии как фундаментальной основы развития нашего общества и государства, а следовательно, и права, и правового регулирования.

Более того, данный вектор вплотную подводит к определению роли сознания и правосознания в формировании идеологических основ жизни человеческого сообщества, к пониманию необходимости сохранения и приумножения человеческого капитала. Именно на этой основе может и должно быть обеспечено создание моделей правового регулирования других различных сфер общественного бытия в целом и каждого человека в отдельности.

Российский традиционализм в оценках человеческого капитала позволяет ученым утверждать, что «сознание занимает центральное место почти во всех аспектах человеческой деятельности. Все, что человек когда-либо познавал или чувствовал, видел, слышал, воображал, во что верил или что получал, в каком бы то ни было опыте, обязательно обрабатывалось универсальным медиумом - сознающим разумом. Сознание - это передаточная система всех наших ценностей, нашего понимания цели и смысла, правильного и неправильного, любви, ненависти, красоты, святости и всего остального, что делает жизнь ценной. Следовательно, всякая существенная ревизия концепции сознания, пересмотр его роли и связи с физическим мозгом или окружающей действительностью будет иметь масштабные последствия» [Сперри, 1994, с. 23].

Сказанное в равной степени относится и к правосознанию, поскольку жизнь в проекции юридической практики, формирующейся на основе официально утвержденной модели правового регулирования общественных отношений, доказывает, что перечисленные выше свойства и признаки сознания имеют прямое преломление и в правосознании. Особое значение доказанности такого присутствия в правовом сознании состоит в том, как подчеркивается в юридической науке, что все без исключения правовые явления предстают в практическом и научном обличии, проходя предварительно через механизмы формирования и функционирования правосознания, а их формализация обеспечивается в процессе правового регулирования [Бутько, Лепешкина, 2021].

В последовательном осмыслении соотношения сознания и правосознания и их роли в сбережении человеческого капитала помогают разобраться исследования академика В.П. Казначеева о многообразии и сложном сочетании многих форм живой материи, воплощенных в самом человеке. Не менее существенным представляется вклад известного хирурга и священнослужителя В.И. Войно-Ясенецкого (Святителя Луки) в понимание сущности и структуры сознания, применительно к проблеме его соотношения с правосознанием [Святитель Лука, 2007]. Такой научный багаж в сочетании с рассуждениями по этой проблематике представителей философии права дает возможность предложить неко- 
торые положения, позволяющие сфокусировать внимание на идеологическом векторе сбережения человеческого капитала.

\section{Противоречия правосознания и права и варианты их разрешения}

Исходным в характеристиках соотношения правосознания и права признается тезис о единстве исторических информационных параметров и источников сознания и правосознания. В этом убеждают известные нам носители информации: мифы, религиозные учения, гипотезы, высказанные интуитивистами и другими феноменальными учеными, которые и могут служить доказательством обозначенного единства. Однако современное право, воздействующее на сознание в этой совокупности, к сожалению, не может считаться совершенным и истинным. Поэтому его применение не улучшает регулирование общественных отношений, не обеспечивает желаемый порядок, а ведет к хаосу, к социальному коллапсу, потому не только не способствует приумножению человеческого капитала, а наоборот способно привести к его существенному сокращению. Этим фиксируется существенное противоречие, возникшее между современным правом и формируемым на его базе правосознанием.

Для разрешения такого противоречия полезным представляется включение в механизмы регулирования иных социальных регуляторов, имеющих в своей основе более весомую нравственную базу и потому более совершенных и надежных. Именно на комплексной системе социальных регуляторов должны быть сформированы основные направления правового регулирования моделей сохранения и наращивания человеческого капитала.

Нуждается в совершенствовании и сам механизм правообразования. Известно, что главным производителем права выступает государство, на него и возлагается ответственность за низкий авторитет права, его противоречивость, пробельность права, за его неспособность защитить законопослушного гражданина от противоправных посягательств. Право, которое мы имеем в настоящее время, создает социальную напряженность, ведет к социальным взрывам, а сформировавшееся на его основе правосознание не может признаваться достаточным и объективированным.

Правосознание наполняется актами нигилизма и отторжения существующего права. Такое положение выступает свидетельством еще одного противоречия, наблюдаемого в механизмах социального регулирования, суть которого состоит в нарушении баланса авторитета производителей разных социальных норм. Его разрешению способствует восстановление баланса такого авторитета.

В подтверждение возможности и целесообразности восстановления сбалансированности прокомментируем некоторые рассуждения таких ученых, как В.П. Казначеев [2004], Б.Ю. Татищев [2012] и другие. В частности, в работах Татищева речь идет о феномене религии как таковом и о самой массовой религии современности.

В высказываниях названных ученых заслуживают внимания суждения о первичности религии как явления, давшего миру соответствующий особый вид социальных норм. Ученые говорят о ее значении первичной базы, включающей этот особый вид в систему социальных регуляторов, о том, что в догударственно-правовой период истории человечества первостепенную роль в регулировании общественных отношений выполняли именно религиозные нормы, являясь высшим видом социальных регуляторов. Их статус первичного социального регулятора должен быть восстановлен хотя бы в тех пределах, в которых они способны будут обеспечить нравственное содержание норм современного права и их соответствие Законам Космоса.

Следующим шагом в этом процессе должно быть признание в качестве одного из источников права, наряду с Земными, космических истоков происхождения права как яв- 
ления, и обеспечение соответствия права позитивного, обогащенного духовным началом, естественному праву.

Сегодня на такую роль претендуют общепризнанные принципы и нормы международного права. Но произведенные в материальном, а не в духовном мире, они не могут выполнить того высокого предназначения, на которое способны Законы Космоса и нормы исторических религий. Тем более что в последние годы наметилась серьезная тенденция к снижению авторитета международного права, все явственнее наблюдаются попытки несоблюдения и даже прямого нарушения его норм.

В большей степени это относится к тем нормам, посредством которых должны быть урегулированы вопросы международной безопасности. Качественно изменились механизмы международно-правовой защиты прав человека, приведшие к появлению так называемого «конвенционного регулирования», настойчиво предлагаемого к имплементации в национальное право. Однако однозначного отношения к ним не наблюдается, поскольку «важнейшей проблемой является обеспечение непротиворечивости взаимодействия этих нормативно-правовых компонентов» [Бондарь, 2010].

И «в перспективе речь должна идти не о стандартах, которые формируются на базе абстрактных принципов, а о выработке общих норм в процессе договоренностей между всеми участниками международного взаимодействия» [Зорькин, 2014].

Предлагаемые варианты решения отмеченных противоречий между правом и правосознанием, таким образом, нацелены на сбережение человеческого капитала посредством совершенствования способов его правового регулирования.

\section{Многоаспектность правосознания в механизмах сбережения человеческого капитала}

Предложенные выше положения подчеркивают распространенные в юридической науке оценки правосознания в интеллектуальном, эмоциональном и волевом аспектах. Их единство в правосознании обеспечивает понимание окружающей правовой действительности в контексте отыскания в ней способов удовлетворения потребностей и интересов человека с помощью права, путем совершения действий, предписываемых правом, если таковое отвечает этим интересам и потребностям.

Именно в таком понимании сознания и правосознания в сочетании с аспектами реальной действительности человек познает самого себя, отвечает на сакраментальный вопрос человеческой жизни - кто есть Я, раскрывая тем самым суть и предназначение человеческого капитала.

В большей степени, чем юриспруденция, объяснение многоаспектности правосознания, а также его взаимосвязи с сознанием в окружающем мире дает философская наука. И не только потому, что знаковым элементом в предмете философии признается вопрос об отношении сознания человека к окружающему миру. Но главным образом потому, что ответ на него составляет основу понимания целей создания и функционирования на планете человеческого капитала.

Однако философские доктрины, разрабатываемые на этот счет, так и не предложили исчерпывающий ответ на поставленный вопрос. Возможной причиной должно признаваться разделение философского мира в зависимости от убеждений и мировоззрений ученых. Напомним лишь некоторые примеры. Так, философы-атеисты не могут разобраться в том, что представляет собой «Дух» в философских учениях Шеллинга, что следует понимать под «абсолютной идеей» в философии Гегеля, что хотел донести до нашего сознания Фихте, обосновывая суть своего «Я».

В конечном итоге состоялось констатирование того факта, что диалектикоматериалистическая философия стоит на позиции понимания сознания как функции высоко организованной материи - мозга. Но по-прежнему представители этого философского 
течения пытаются безуспешно разгадать, каким образом информация, получаемая органами чувств человека, преобразуется в образ, отображаемый его сознанием.

Обращаясь к исследованиям представителей естественных наук (Экклз, 1959 г., Пенфилд,1975 г.) невольно приходится соглашаться с ними в том, что человек не может мыслить за счет работы мозга, так же, как и с мнением Л.А. Латышевой в том, что «обладая уникальным инструментом для познания мира, о самом этом инструменте мы строим лишь более или менее правдоподобные предположения» [Латышева, 1998, с. 197].

Вполне возможно, что в конечном итоге человечество согласится с необходимостью привлечения постнаучного мышления, которое все явственнее заявляет о себе в условиях цифровизации и создания искусственного интеллекта. К примеру, Л.А. Латышева считает, что такая работа, как терпимое отношение к инакомыслию, к плюрализму идей и мнений, «оказывается выполнимой лишь на новом уровне мышления, отличном от научного. Назовем его ПОСТНАУЧНЫМ, - предлагает философ, - и будем понимать под ним всю совокупность методов и способов познания, которую выработало человечество во всех сферах своей духовной жизни - в философии, религии, науке, политике, праве, морали и искусстве. Не станем игнорировать и так называемые мистические способы познания - Интуицию, Откровение, Озарение, Экстаз» [Латышева, 1998, с. 7].

Примеры такого мышления в истории человеческой мысли в различных отраслях знаний, включая юридическую науку и практику, преподнесли (кроме названных В.П. Казначеевым) Платон, Аристотель, Цицерон, Фома Аквинский, Д. Бруно, Ф. Лейбниц, И. Кант, Ф. Гегель, П. Флоренский, С. Булгаков, И. Ильин и другие ученые. Ими вполне обосновано выдвигалась идея единого знания, включающего эмпирические, рациональные и иррациональные начала. Совокупность таких знаний наблюдается в содержании правосознания, чем и предопределены его возможности в сбережении человеческого капитала.

\section{Заключение}

С учетом сказанного, а также исходя из сопоставления особой значимости правового сознания с его современным кризисным состоянием, вытекает необходимость определить главный вектор исследовательского поиска в решении проблем сбережения человеческого капитала, наполнения сознания человека духовным стержнем как реализации его божественного начала.

Напоминая слова И.А. Ильина о том, что «кризис современного культурного правосознания состоит в теснейшей связи с религиозным кризисом» [Ильин 2005, с. 246], дополним: в связи со всемирным социально-экономическим и финансовым кризисом, экологическим неблагополучием, коронавирусной пандемией и другими наблюдаемыми явлениями. Особо подчеркнем, что в состоянии политического кризиса человечество находится уже не одно столетие. Вся современная действительность служит доказательством такого кризисного состояния. И представлено оно такими явлениями, как разноликая преступность, экстремизм, терроризм, коррупция, массовые беспорядки, государственные перевороты, революции, войны и т.д., демонстрируемые на религиозной, национальной и иной почве не только локально, но и во всемирных масштабах.

Предложенные в статье обоснования актуальности, значения, содержания и варианты решения поставленных проблем сбережения человеческого капитала сориентированы на философские трактовки его духовного наполнения и необходимость совершенствования правового регулирования данной сферы общественных отношений. В оценках новаций его правового регулирования в ключе конституционных поправок заслуживает внимания позиция Р.А. Папаяна. Он, в частности, утверждает, что «ученый, считающий себя... приверженцем христианских ценностей, призван исследовать и открывать в природе и в жизни закономерности Божьего творения, будь то в области астрофизики или права. И тогда правовые нормы будут не сочиняться, а открываться. Ибо сказано: "Что 
было, то и будет; и что делалось, то и будет делаться, - и нет ничего нового под солнцем. Бывает нечто, о чем говорят - смотри, вот это новое; но это было уже в веках, бывших прежде нас. Нет памяти о прежнем" (Екк. 1.9. - 11)» [Папаян, 2002, с. 1]. Сказанное следует дополнить призывом поступать по тем же правилам и тех, кто исповедует иные религиозные ценности.

Нас же убеждают в правильности сочиненных человеческим умом норм, в том, что незачем эти нормы «открывать», достаточно их «сочинить», обеспечить их действие и применение принудительной силой государства и требовать неукоснительного подчинения этим нормам всех и вся. Настала пора согласиться наконец с явной философскогносеологической недостаточностью, а порой и пагубностью таких пониманий права и сформированного на его основе правового регулирования. Нельзя относиться к данному феномену так поверхностно.

С учетом изложенных выше философских рассуждений, представляется целесообразным дефинитивное и методологическое обновление концептуальных положений учения о правовом регулировании общественных отношений в сфере сбережения человеческого капитала, сложившегося и проповедуемого в отечественной юриспруденции в течение последних десятилетий. Такой подход в реформировании системы правового регулирования способен обеспечить решение его назревших проблем дефинитивнологического и практического толка, а также достижение цели создания и внедрения современных теоретических конструкций обновленной модели государственности нового исторического типа в Российской Федерации.

\section{Список литературы}

1. Бондарь Н.С. 2010. Европейский конституционализм в аспекте национальной конституционной и европейской конвенционной юрисдикций. Рабочие материалы к Международному форуму по конституционному правосудию 18-20 ноября 2010, http://www.ksrf.ru/ru/news/Documents/ Bondar.pdf (Дата обращения: 21.03.2021)

2. Бутько Л. В., Лепешкина О.В. 2021. Некоторые проблемы правового регулирования общественных отношений в ключе новых конституционных изменений. В кн.: Конституционная реформа в России 2020 года: политическое и правовое значение. Материалы всероссийской научнопрактической конференции с международным участием (4 декабря 2020 года). Краснодар, 2021: 28-32.

3. Зорькин В.Д. 2014. Цивилизация права: современный контекст. Журнал конституционного правосудия, 5: 1-15.

4. Ильин И.А. 2005. Кризис безбожия. М., 496 с.

5. Казначеев В.П. 2004. Думы о будущем. Рукописи из стола. Новосибирск, 208 с.

6. Латышева Л.А. 1998. Философия чуда. «Сталкер». Донецк, 336 с.

7. Папаян Р.А. 2002. Христианские корни современного права. М., 416 с.

8. Святитель Лука. 2007. Архиепископ Симферопольский и Крымский. Дух, душа и тело. Избранные творения. М., 767 с.

9. Сперри Р.И. 1994. Перспективы менталистской революции и возникновение нового научного мировоззрения. Мозг и разум. М., $176 \mathrm{c.}$

10. Татищев Б.Ю. 2012. Древнейшие Боги планеты. М., 272 с.

\section{References}

1. Bondar' N.S. 2010. Evropejskij konstitucionalizm v aspekte nacional'noj konstitucionnoj i evropejskoj konvencionnoj yurisdikcij [European constitutionalism in the aspect of national constitutional and European convention jurisdictions]. Rabochie materialy $\mathrm{k}$ Mezhdunarodnomu forumu po konstitucionnomu pravosudiyu November 18-20, 2010. http://www.ksrf.ru/ru/news/ Documents/Bondar.pdf (Accessed: 21.03.2021)

2. But'ko L.V., Lepeshkina O.V. 2021. Nekotorye problemy pravovogo regulirovaniya obshchestvennyh otnoshenij $\mathrm{v}$ klyuche novyh konstitucionnyh izmenenij [Some problems of legal regulation of public relations in the context of new constitutional changes. Constitutional reform in 
Russia in 2020: political and legal significance]. In: Konstitucionnaya reforma v Rossii 2020 goda: politicheskoe i pravovoe znachenie. [Constitutional reform in Russia in 2020: political and legal significance]. Materials of the All-Russian scientific and practical conference with international participation (December 4, 2020). Krasnodar, 2021: 28-32.

3. Zor'kin V.D. 2014. Civilizaciya prava: sovremennyj kontekst [The Civilisation of Law: a modern context]. ZHurnal konstitucionnogo pravosudiya, 5: 1-15.

4. Il'in I.A. 2005. Krizis bezbozhiya [The crisis of godlessness]. M., 496 p.

5. Kaznacheev V.P. 2004. Dumy o budushchem. Rukopisi iz stola [Thoughts about the future. The manuscripts from the table]. Novosibirsk, $208 \mathrm{p}$.

6. Latysheva L.A. 1998. Filosofiya chuda [The philosophy of the miracle]. Stalker. Doneck, 336 p.

7. Papayan R.A. 2002. Hristianskie korni sovremennogo prava [Christian roots of modern law]. M., $416 \mathrm{p}$.

8. Svyatitel' Luka. 2007. Arhiepiskop Simferopol'skij i Krymskij. Duh, dusha i telo. Izbrannye tvoreniya [Archbishop of Simferopol and Crimea. Spirit, soul and body. Selected creations]. M., 767 p.

9. Sperri R.I. 1994. Perspektivy mentalistskoj revolyucii i vozniknovenie novogo nauchnogo mirovozzreniya. Mozg i razum [The prospects of the mentalist revolution and the emergence of a new scientific worldview. Brain and mind]. M., $176 \mathrm{p}$.

10. Tatishchev B.YU. 2012. Drevnejshie Bogi planet [The oldest Gods of the planet]. M., 272 p.

Конфликт интересов: о потенциальном конфликте интересов не сообщалось.

Conflict of interest: no potential conflict of interest related to this article was reported.

\section{ИНФОРМАЦИЯ ОБ АВТОРАХ}

Бутько Людмила Васильевна, доктор юридических наук, профессор, профессор кафедры административного и финансового права СКФ ФГБОУ ВО «РГУП», г. Краснодар, Россия.

Лепешкина Ольга Владимировна, доцент, кандидат юридических наук, доцент кафедры теории и истории государства и права Кубанского государственного университета, г. Краснодар, Россия.

\section{INFORMATION ABOUT THE AUTHORS}

Ludmila V. Butko, Doctor of Law, Professor, Professor of the Department of Administrative and Financial Law of the NCF FGBOU VO "RSUP", Krasnodar, Russia.

Olga V. Lepeshkina, Associate Professor, Candidate of Legal Sciences, Associate Professor of the Department of Theory and History of State and Law of Kuban State University, Krasnodar, Russia. 